Dhaka Univ. J. Biol. Sci. 22(1): 29-37, 2013 (January)

\title{
LOSS AND GAIN OF LAND OF MANPURA ISLAND OF BHOLA DISTRICT: AN INTEGRATED APPROACH USING REMOTE SENSING AND GIS
}

\author{
Md. Shahjahan Ali ${ }^{1}$, Md. Fazlul Haque ${ }^{1}$, Shah Md. Mizanur Rahman ${ }^{1}$, Kazi \\ FARHED IQUBAL ${ }^{2}$, NAZMA $^{3}$ AND Ashfaque AHMED* \\ Department of Botany, University of Dhaka, Dhaka-1000, Bangladesh
}

Key words: Meghna estuary, Manpura Island, Land erosion, Mangroves, Remote sensing

\begin{abstract}
The erosion-accretion pattern in Manpura island has been depicted over a 37 years period from 1973 - 2010. Data of different years revealed that the island is under the threat of erosion and the total area has gradually decreased from 148 to $114 \mathrm{Km}^{2}$. Although Manpura island is under the threat of erosion, some lower mid parts get in irregular erosion - accretion processes, where area of water bodies has decreased up to a significant level $\left(15 \mathrm{Km}^{2}\right)$ and the area of mangrove forests have also decreased to $6 \mathrm{Km}^{2}$. According to this study, total land loss of Manpura island is $34 \mathrm{Km}^{2}$ in the last 37 years and major erosion took place along the northern shore line.
\end{abstract}

\section{Introduction}

The Meghna estuary is a very dynamic estuarine and coastal system where rates of erosion and accretion are very high. The rivers widen severely eroding their banks. The offshore islands gradually migrate southwards, and the mainland builds out towards the estuary $^{(1)}$. Sediment concentrations are high in the entire estuary, not only during the wet monsoon season but also in the dry season resulting in the accretion of small islands(1). Tidal currents are generally strong enough to maintain sediments in suspension. The river-borne sediments become trapped in the estuary by the effects of pumping residual circulation $^{(2)}$

Tidal action is also a highly dynamic phenomenon that varies not only with the seasons of the year but also change throughout the year resulting in an ever changing geography. The waves from the Indian Ocean travel rather fast through the depth of the Bay of Bengal and arrives at Cox's Bazar and Hiran Point at about the same time(3). The shallow area in front of the delta causes some refraction and distortion of the tidal wave. Through a deep tidal inlet in the eastern part of the Bay, the tides travel fast along the

*Author for correspondence. <aashfaque67@yahoo.com>. 1Bangladesh Space Research and Remote Sensing Organization (SPARRSO), Ministry of Defense (MoD), Government of Bangladesh. ${ }^{2}$ Department of Environmental Science, State University Bangladesh. ${ }^{3}$ Local Govt. Engineering Department, Government of Bangladesh. 
eastern coast while numerous shoals and islands in the west offer frictional resistance to the propagation of waves, resulting in a phase lag between the eastern and western part of the estuary. Due to this phase lag and difference in tidal range, an east-west current is developed during the rising tide ${ }^{(4)}$.

The estimated average annual sediment load carried by the rivers of Bangladesh to the Bay of Bengal is around 2 billion tons annually(5). The Ganges and the Brahmaputra are heavily laden with fine sediments. The Ganges river carries fine sediments with a heavy clay load whereas the Brahmaputra river particularly transports fine sand and silt in suspension. The Meghna river appears to be a relatively low sediment laden river. Of the three rivers, the share of Ganges with annual average concentration of $1300 \mathrm{mg} /$ and the Brahmaputra with $1000 \mathrm{mg} /$ is almost equal while the share of Meghna with $100 \mathrm{mg} \Lambda$ is about one-tenth ${ }^{(4)}$.

The Ganges-Brahmaptra-Meghna (GBM) river system with their numerous tributaries and distributaries carry, distribute and dispose water and sediments in the Bengal Basin including deltaic part and the Bay of Bengal. The Ganges, Jamuna and Brahmaputra rivers coalesce into the Meghna in the basinal part and then fall into the Bay of Bengal. The huge influx of suspended sediments which are carried out to the Bay of Bengal, by these mighty rivers system, the GBM system, resulted in the formation of many offshore islands( ${ }^{(6)}$. The Manpura Island which is situated at Meghna estuary is one of them.

The Meghna estuary passed through many changes during the last 200 years. The major changes were the migration of channels and growth of some new islands in the southern part. In Rennell's map of 1789, the Meghna was found to flow in an easterly direction with some southerly flowing minor distributaries ${ }^{(7)}$. In 1898, within a time span of 109 years, the main flow of Meghna bifurcated into two channels, one to the east and the other to the west of Hatia island. In 1945, within a period of 45 years, the strength of the current of the eastern channel became weak with the domination of the southerly flow which is called the Shahbazpur channel. A $12 \mathrm{~km}$ long Meghna cross dam-1 was constructed in 1957, which diverted the direction of the flow towards the south through the Shahbazpur channel ${ }^{(6)}$. The channel is divided into two downward parallel directions keeping the Manpura island in the middle. The strong downward flow tends to cause erosion to the frontier shore and in some adjacent lower parts of the island.

Remote sensing imagery provides information about various land form types in spatial format which is useful for erosion assessment ${ }^{(8)}$. It is an important supplement to ground observations and to build up the paleographic records of earth resources. The rapid evolution in satellite remote sensing in terms of spatial, spectral, radiometric and temporal resolutions of different sensors and the availability of earth related synoptic data in digital format have revolutionized the techniques for resource planning and their management. 
The present study is aimed to estimate the erosion and the accretion of landmass of Manpura island using Landsat MSS and TM images over the period of 37 years since 1973. Using of remotely sensed data provides many advantages including synoptic coverage, availability of low-cost or free satellite data, availability of historical satellite data, and repeated coverage. With the advances in the hardware and software used for processing a large volume of satellite data the usefulness of remotely sensed data has increased ${ }^{(9)}$. The study resulted in preparation of paleographic map and physiographic data of the island. The accrued information may provide help for further study and for taking up the plan for development activities of Manpura island.

\section{Materials and Methods}

The present study has been conducted on Manpura island under Bhola district which lies within $90^{\circ} 52.28^{\prime} \mathrm{E}$ to $22^{\circ} 20.85^{\prime} \mathrm{N}$ and $90^{\circ} 98.00^{\prime} \mathrm{E}$ to $22^{\circ} 02.63^{\prime} \mathrm{N}$. It is situated in the northern part of the Bay of Bengal, at the mouth of the Meghna river. Manpura island is bounded on the east by the Hatiya island and on the west by Shahbazpur channel, on the north by Char Patlia and Char Nizam. The island's south side is open to the Bay of Bengal. The study was conducted on the main Manpura island. As there are no other stable small islands close to or around the main island, the changing geomorphological effects over the entire area are not much more important for study.

The Manpura island is a flat landmass; the highest peak is around three meters above the sea level. There are some highlands on the island, but these are man-made, like roads and embankments. The soil of the Manpura island is calcareous alluvium and saline ${ }^{(10)}$. Begum et al. ${ }^{(11,12)}$ have studied the morphological, mineralogical and edaphologiccal aspects of soil of Manpura island and found predominately loamy soil with an average content of $51 \%$ silt and $21 \%$ clay with colours varying from very dark grey to dark grey. It is seasonally flooded, poorly drained and developed in very young medium textured deposits. It occurs extensively on the young lower Meghna estuarine floodplain ${ }^{(3)}$. The climate of the study area is typical monsoonal. Based on the pressure, rainfall and temperature, the climate of the island can be described under four seasons: (a) winter, (b) summer of pre-monsoon, (c) monsoon and (d) autumn of post monsoon.

The tidal waves from Indian Ocean travel rather faster through the deep Bay of Bengal. These waves arrive at Cox's Bazar and at Hiron Point of Khulna at about the same time ${ }^{(3)}$. The extensive shallow area in front of the delta causes some refraction and distortion of the tidal waves. As a result, the waves bunch up and hits the islands, especially at the lower and its associated east and west surroundings, which causes the erosion of the islands (Fig. 2). 


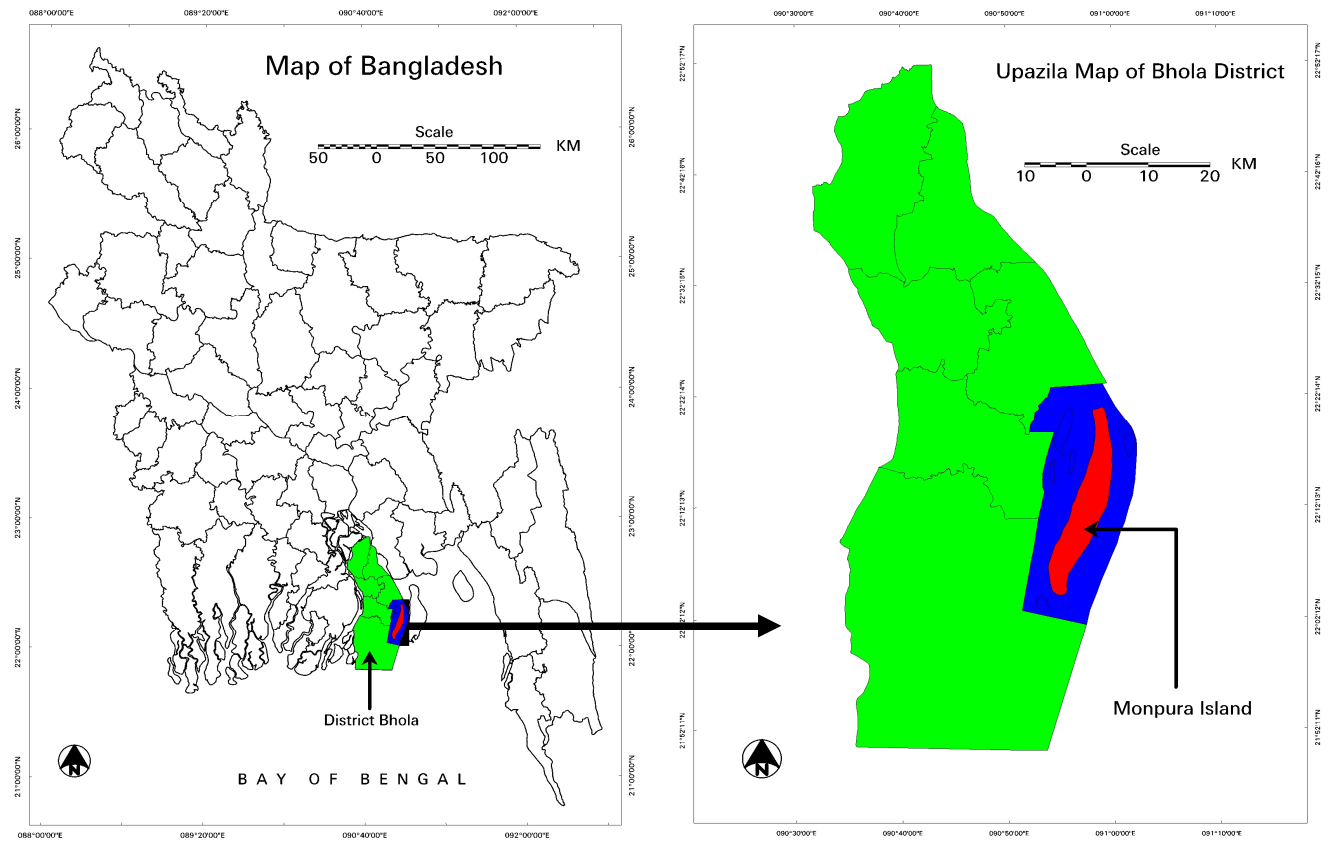

Fig. 1. Location of the study area within Bangladesh.

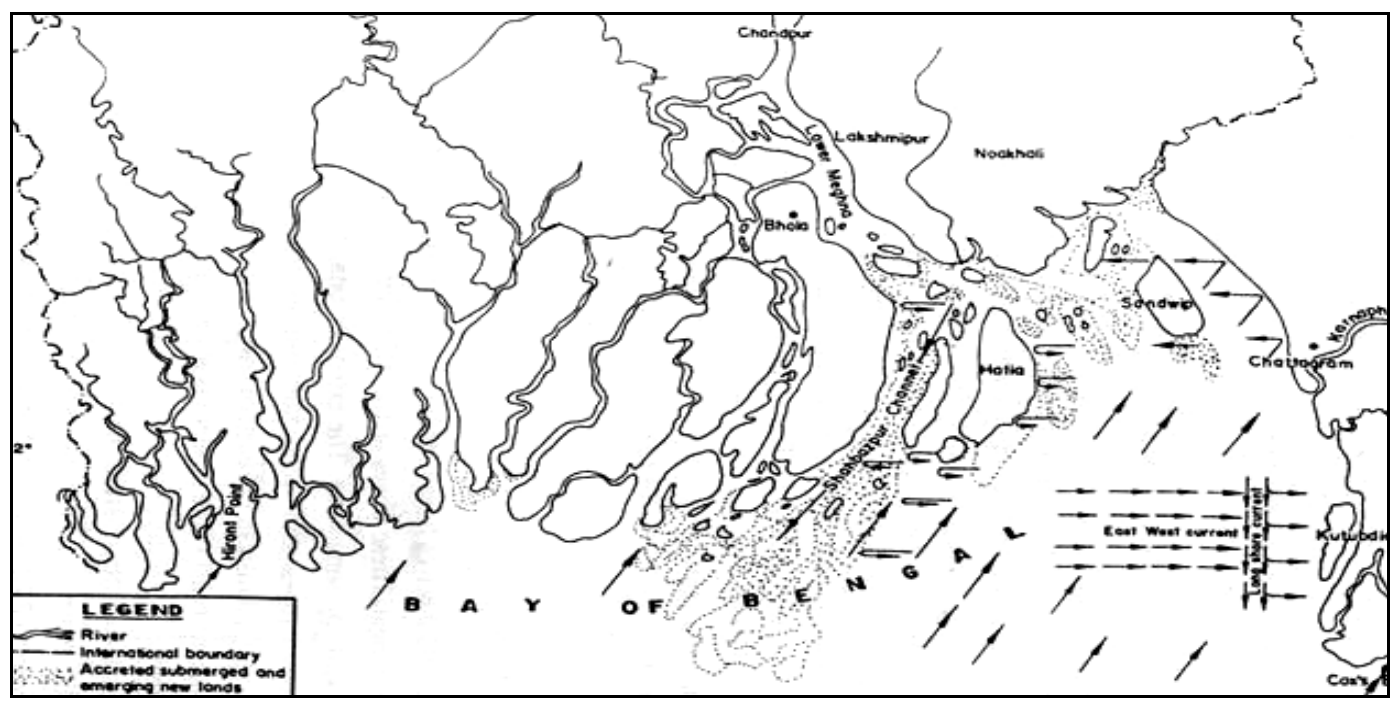

Fig. 2. The wave direction in the Bay of Bengal.

The bottom topography of the surrounding areas of Manpura island is characterized by numerous submerged shoals and barrier bars. Water moving over these shoals and barrier bars induces complicated turbulence which can also be a reason for erosion of the island ${ }^{(3)}$. 
Waves significantly influence the erosion and depositional process, especially during monsoon. The south-west monsoon tends to accumulate water in the north-eastern part of the Bay. This accumulated water together with the huge monsoonal water of the channels affect the sea-level and cause swelling of water at about one meter which may stimulate erosion ${ }^{(3)}$

As it has been mentioned that due to the building of cross dams (Meghna cross dam1 and cross dam-2), the position of flow direction of the former channels have been laterally migrated from east toward the west. As a result of this the Shahbazpur channel became prominent. The channel was divided into two southward parallel directions, keeping the Manpura island at the middle of its flow. The strong downward current of the channel hits the upper frontier of the island which causes its erosion ${ }^{(3)}$.

In the present study, satellite data, available published maps, reports and secondary data have been used. Landsat MSS images of different periods, from 1973 to 2010 (Table 1) has been used for quantifying the landmass areas of Manpura island. All the images were received in the winter season, when normally the sky is clear and cloud free. Landsat satellite passes the coastal area of Bangladesh after 10 minutes of its crossing the equator at 09.30 a.m. local time. Water level data has been taken from yearly tide table published by Department of Hydrography, Bangladesh Inland and Water Transport Authority. The water level data were recorded at Char Chunar station of south-west Hatia coast, which is adjacent to the east Shahbazpur channel. Normally, the tidal waves in the Bay of Bengal rise up to three meters from its normal level. From the recorded values of water height, it is seen that, Landsat MSS of 1980 and TM of 1989 images are at high/medium high period and rest two images are during very low tidal conditions. Tidal record for Landsat MSS image of 1973 was not found in the record table.

The methodology adopted for this study involves both the digital image processing and GIS based analysis. Landsat images were geometrically corrected and geo-referenced with respect to an existing corrected Landsat image using the Raster Module of ERDAS Imagine. The RGB colour composites images were prepared for the study as shown in Table 1.

Standard visual interpretation method based on tone, texture, pattern, shape and size of the features was used for extraction of necessary information. Mainly three layers of information were extracted, like landmass, river and mangrove forest areas from all the five temporal images.

Arc Info software was used for generating the topology of the extracted layers and attributes were added in the attribute table for each theme and a spatial database was created. Three generated spatial data layers were then considered for analysis based on 
the estimation of erosion and accretion pattern of landmass of the island over the period of 37 years from 1973 - 2010. A composite paleographic map was prepared comprising the interpreted landmass boundaries of the island which showed the configuration of Manpura island over the said historical period.

\section{Results and Discussion}

The study has identified both the accretion and the erosion patterns by preparing a paleographic map of the Manpura island during a span of 37 years (1973 - 2010). Massive changes have occurred in the northern shore of the island. Total of $3.0 \mathrm{~km}$ of land from top northern part of the island was eroded away during the period of 37 years. During this period, the island lost land along 500 meters laterally along the entire east side and about 800 meters of land was dropped into the sea along the north west half of the island. The island also lost its 400 hectares of land in its southern extremity over the said historical period. A regular pattern of erosion is observed along both the sides of northern half, whereas some exceptions were noticed along the lower and mid-lower part of the island (Fig. 3).

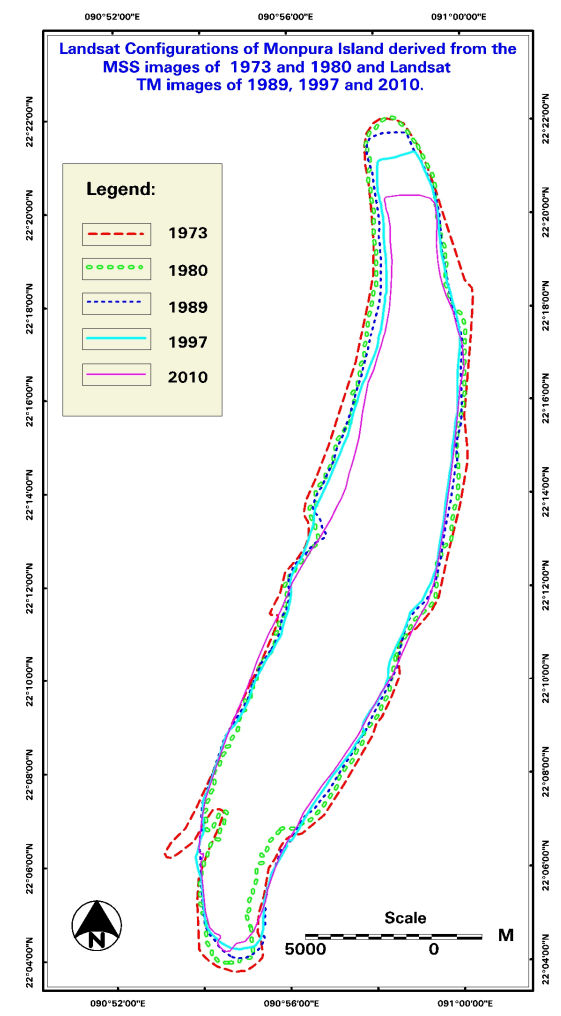

Fig. 3. Map showing the configuration of Manpura island over the period 1973 - 2010. 
Comparative study of the years 1973, 1980, 1989, 1997 and 2010 revealed that the total area of the island gradually decreased from 148 to $114 \mathrm{Km}^{2}$. Rates of land erosion $\left(\mathrm{Km}^{2} /\right.$ year) were 2.57, 0.016, 1.0 and 0.55 through the years 1973-1980, 1980-1989, 19981997 and 1997-2010. So, the general decreasing trend of the landmass of Manpura island points out that the island is under the stress of erosional process. Erosion is more active in southern and northern extremity of the island (Fig. 4) where the total eroded area was found to be $34 \mathrm{Km}^{2}$.

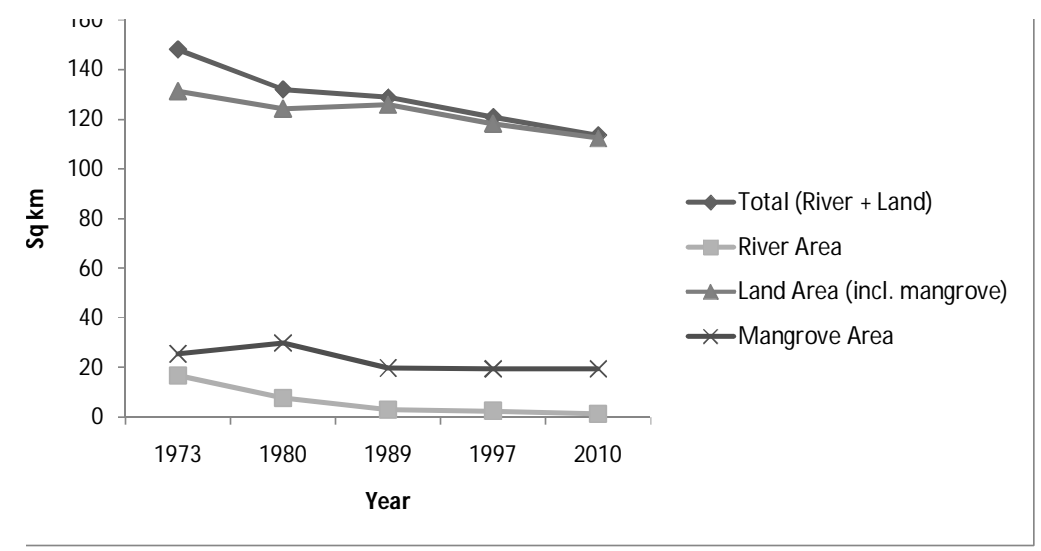

Fig. 4. Change of total land area of Manpura Island from 1973 to 2010 and its probable trend of erosion.

Considering the high and low tide phenomenon, it can be analyzed that, landmass areas acquired from the low tide hours' images of 1997 and 2010 are found to be smaller than high tide periods' image of 1980 and 1989. The difference of landmass areas would have been much higher if the images of 1980 and 1989 were taken during low water level hours. So, the gradual decreasing result of landmass over the periods minimizes the questions of using the images in different tidal level conditions.

The study also revealed that total water body area decreased from 17 to $1 \mathrm{Km}^{2}$. This was because of the huge downward sediments entering in the river from upper stream, which got trapped in by the upward bumping tidal flow from the bay. As a result, river levels are filled up and total inland water area was decreased (Table 2). From Table 2 the statistics of mangrove forest in the island shows that, in 1973 total mangrove area was 26 $\mathrm{Km}^{2}$, which was reduced to $20 \mathrm{Km}^{2}$ by 2010 . Before 37 years, extensions of mangrove areas were done mainly along the inland river banks and on the lower part of the island. There were also some planted mangrove areas surrounding the sea shore region of the island. As the rivers were narrowed down due to human interference, most of the 
mangrove areas in the mid and upper part of the island have been diminished. But it is observed that much dense mangrove areas have been developed in the southern part and the same situation is prevailing since 1997, which are helping in some way to protect the extreme southern tip of the island. Ahmed et al.(13) reported the changes of mangrove vegetation, river and canals and land area of Sundarban Mangrove Forests (SMF) of Bangladesh for a period of 21 years which showed an increasing land mass of two Ranges for 1989 to 2000 which subsequently decreased in the next decade (2000 to 2010). Giri et al.(9) reported an increase in the net forest area by $1.4 \%$ from the 1970 s to $1990 \mathrm{~s}$ and a decrease by $2.5 \%$ from 1990 to 2000 of the total Sundarban Mangrove Forest of both Bangladesh and India.

Table 1. Characteristics of Landsat data used for the study.

\begin{tabular}{lccc}
\hline Data (Bands RGB) & Date & Intervals & Tidal height \\
\hline Landsat MSS(421) & 02 Feb. 1973 & -- & -- \\
Landsat MSS(421) & 15 Jan. 1980 & 07 years & 2.12 m \\
Landsat TM(432) & 12 Jan. 1989 & 09 years & $1.90 \mathrm{~m}$ \\
Landsat TM(432) & 19 Jan. 1997 & 08 years & $0.62 \mathrm{~m}$ \\
Landsat TM(432) & 30 Jan. 2010 & 13 years & $0.44 \mathrm{~m}$ \\
\hline
\end{tabular}

Table 2. Area $\left(\mathrm{Km}^{2}\right)$ statistics of generated layers of Manpura island.

\begin{tabular}{ccccc}
\hline Year & $\begin{array}{c}\text { Total } \\
\text { (river + land) }\end{array}$ & River & $\begin{array}{c}\text { Land } \\
\text { (including mangrove) }\end{array}$ & $\begin{array}{c}\text { Mangrove } \\
\text { forests }\end{array}$ \\
\hline 1973 & 148 & 16.80 & 131.35 & 25.56 \\
1980 & 132 & 7.83 & 124.28 & 29.84 \\
1989 & 129 & 3.00 & 125.90 & 19.89 \\
1997 & 121 & 2.63 & 118.26 & 19.55 \\
2010 & 114 & 1.42 & 112.29 & 19.54 \\
\hline
\end{tabular}

Remote sensing data have been utilized in quantifying the change of landmass pattern of Manpura island. The paleographic map of the island was prepared using Landsat MSS and Landsat TM multi-date and multi-spectral imagery over the period of 1973 - 2010.

Although, the study has been carried out on both the erosion and accretion history of the island, special emphasis was given on the erosional process of landmass. It is because of the continuous erosion process of the land area that dominated the very few accretion events which occurred during the study period.

The study demonstrated the changing landmass of the main Manpura island only. A few far-off submerged islands which are visible in low tide conditions were not considered in this study. 
The depletion of mangroves in the upper part of landmass and strong downward pressure of water through Shahbazpur channels along with bumping tides and long shore current are the causal factors in land erosion of the island.

This study would be helpful to conduct the temporal physiography and to some extent, the natural phenomenon for initializing the development plan of Manpura island.

\section{Acknowledgment}

Mr. Muzibur Rahman Howlader, (Chairman, SPARRSO, Dhaka) has given guideline and permission for using the recent satellite images of the Manpura island and some other relevant information and publications to the authors. The support from this organization is highly appreciated.

\section{References}

1. Ahmed A, M Ohlson, S Hoque and MG Moula 2010. Edaphic conditions under different hydrological regimes in the coastal zone of Bangladesh. Dhaka Univ. J. Biol. Sci. 19(1): 27-40.

2. Saifuddin A 1996. Residual tidal and sediment volume, their circulation patterns and land cover changes in the Meghna estuary. J. Civil Engineering 26(1): 61-83

3. Tarafder SA 1995. Stratigraphical and Hydro-chemical investigations of the Kutubdia Island with special reference to the geological evolution. Final Report, Dhaka.

4. Skidmore AK, W Bijker, K Schmidt and L Kumar 1997. Use of remote sensing and GIS for sustainable land management. ITC Journal 3-4: 302-315.

5. Potdar SS, R Srivastava, MSS Nagaraju, J Prasad and RK Saxena 2003. Mapping of erosional soil loss in Nanda-Khairi watershed of Nagpur district of Maharashtra using remotely sensed data and GIS techniques. Agropedology 13: 10-18.

6. Burrough PA and RA McDonnell 1998. Principals of Geographical Information Systems, Oxford University Press.

7. Choudhury NV 1973. Remote sensing of natural resource of Bangladesh through Earth Resource Technology Satellite Programm.

8. Saha SK and BM Singh 1991. Soil erosion assessment and mapping of Aglar river watershed (U.P.) using remote sensing technique. J. Indian Society of Remote Sensing 19: 67-76.

9. Giri C, B Pengra, Z Zhu, A Singh, LL Tieszen 2007. Monitoring mangrove forest dynamics of the Sundarbans in Bangladesh and India using multi-temporal satellite data from 1973 to 2000. Estuar. Coast. and Shelf Sci. 73: 91-100.

10. Durand JM and Y H Kerr 1989. An improved decorrelation method for the efficient display of mulhspectral data, IEEE Trans. Geosci. Remote Sens 27(5): 611-619.

11. Begum A, MS Hussain, SM Ullah and F Ottner 2004. Morphological and mineralogical features of some soils from Manpura island in Bangladesh. J. Asiat. Soc. Bangladesh, Sci. 30(1): 17-24. 
12. Begum A, MS Hussain and SM Ullah 2004. A study of pedological and edaphological aspects of the Manpura island in coastal area of Bangladesh. S. Asian J. Agric. 1(2): 84 - 91.

13. Ahmed A, A Aziz, AZMNA Khan, MN Islam, KF Iqubal, Nazma and MS Islam. 2011. Tree diversity as affected by salinity in the Sundarban Mangrove Forests, Bangladesh. Bangladesh J. Bot. 40(2): 197-202.

(Manuscript received on 28 April, 2012; revised on 7 January, 2013) 